Felisberto Cavalheiro, engenheiro agrônomo e doutor em arquitetura paisagística

(Universidade de Hanover) e professor da Unesp.

Luciana Studart Lins de A. Andrade, arquiteta (UnB).

Mônica Aires Cardoso, bióloga, bacharel em ecologia e botânica (UnB). Atua na

Coordenação de Estudos de Ecossistema
Felisberto Cavalheiro

Luciana Studart Lins de A. Andrade

Mônica Aires Cardoso

da SEMA.

\title{
Ecologia urbana: o planejamento e o ambiente alterado das cidades
}

\section{Introdução}

O tema ecologia urbana é, na verdade, bastante recente. A tendência sempre foi a de se pesquisar os fatores componentes do complexo paisagem em ambientes naturais, podendo-se mesmo afirmar que pesquisadores das bio e geociências tendem a evitar as cidades, já que elas não se enquadram no esquema idealístico das ciências naturais, pois, no geral, seriam nocivas à vida.

Já pesquisadores de ciências hụmanas evitam relacionar o homem em seu ambiente, pois vêem nisso resquícios do determinismo que procura explicar o comportamento do ser humano em função do ambiente em que vive.

Somos levados a crer que a lacuna existente em pesquisa, no que se refere aos fatores naturais componentes do ambiente urbano, entre outras razões, deve-se às hipóteses que relatamos.

Urge que essa deficiência comece a ser sanada o quanto antes, já que, segundo prognósticos, $50 \%$ da população mundial viverá em cidades com mais de vinte mil habitantes no ano de 1990, enquanto que em 1960 essa relação era de 30\% (Recchini, 1969).

A situação brasileira não foge a essa tendência, pois segundo dados do IBGE que, na verdade, não diferencia cidades de vinte mil habitantes ou menos, cerca de $61 \%$ dos brasileiros viviam em cidades em 1976, enquanto que em 1960 eram apenas $45 \%$. No caso de estados mais urbanizados como São Paulo, 87,5\% da população em 1976 era urbana.

Era de se esperar, portanto, que grande parte das pesquisas em ecologia fossem feitas nesses ambientes habitados pela maioria da nossa população. Talvez tivéssemos nesse caso, pelo menos, explicações para problemas de enchentes e de aumento desproporcional da população de ratos e baratas em centros urbanos.

No entanto, esses problemas, ditos urbanos, são enfocados por especialistas de áreas, sem uma visão ecológica, que tentam sanar o "dominar" os problemas de modo tecnicista, sem tentar entender como funcionam os ecossistemas. Assim, procurase solucionar os problemas das enchentes com canalização e retificação de cursos d'água e diminuir as populações de ratos, com campanhas caríssimas e sofisticadas.

Acontece que, até hoje, essas medidas tecnicistas, que concentram suas atenções de forma desordenada, tentando solucionar problemas isolados que aparecem no ar, água ou em relação a rejeitos, têm sido ineficazes. Necessário se faz que a paisagem urbana seja encarada como um sistema complexo, em que os componentes naturais: clima, subs- 
trato, água, vegetação e fauna relacionam-se, criando uma interdependência. Por isso julgamos muito apropriado a aplicação do termo "ecossistema urbano", pois transmite essa idéia dinâmica de interrelação.

Com nossas observações não queremos, entretanto, tirar o mérito da pesquisa nos ambientes naturais. Elas são importantíssimas, já que nos forneceram o embasamento para podermos avaliar o quanto os ecossistemas artificiais, criados pelo homem, funcionam diferente. o que se pretende é enfatizar a urgência de se começar a pesquisar as cidades como ecossistemas artificiais e não seus fatores isolados como poluição do ar, inundações, etc.

\section{Ambiente natural}

Como dissemos, de nada adiantaria pesquisar os ecossistemas artificiais, se não soubessemos o funcionamento dos naturais. Infelizmente, muito pouco se sabe sobre os ecossistemas naturais de regiões tropicais. No geral, extrapolam-se conclusões existentes sobre ecossistemas de clima temperado e frio para ecossistemas de clima tropical e subtropical, citando-se como exemplo o do revolvimento da terra antes do plantio, válido para regiões frias, por provocar um aquecimento mais rápido do solo e que até hoje vem sendo efetuado em regiões tropicais, sem uma explicação coerente para o fato.

Neste ponto, faz-se necessário que expliquemos, de forma simplificada o termo ecossistema: consiste da interação de todos seres vivos (parte biótica) entre si e com o substrato inorgânico (parte abiótica) de uma região, com trocas de energia.

A energia solar entra no sistema através das plantas, que a transforma em energia química utilizável por alguns indivíduos que, por sua vez, podem ser consumidos por outros. Essa seqüência de organismos na qual um come o outro é chamado cadeia alimentar, e os termos produtor, consumidor de primeira, segunda e terceira ordens como também decompositor, representam os níveis trópicos dessa cadeia. Quanto mais indivíduos participarem dessa cadeia, mais diversificado é o ecossistema e maior a sua capacidade de regeneração, quando de intervenções externas, apesar de serem mais frágeis.

Para nosso estudo é importante que fique claro que energia e matéria circulam e são recicladas em todas as inter-relações que ocorrem nos ecossistemas, fazendo com que o equilíbrio seja dinâmico.

Justamente nessa circulação o homem pode interferir, consciente ou inconscientemente, alterando o equilíbrio, sendo as cidades um dos melhores campos de estudo para essas interveniências.
Ecossistemas artificiais/ecossistemas. urbano-industriais

Como vimos, o ambiente natural é moldado pela interação dos diversos fatores que o formam e temos a visualização dessas inter-relações no plano físico, através da paisagem.

Em outros tempos, a atuação do homem no ambiente natural não era suficientemente grande para causar uma mudança significativa da paisagem, o que de certa forma ainda é válido para sociedades primitivas, como nossos índios. Entretanto, hoje, nas sociedades modernas o que se nota é uma ação do homem alterando, justamente, as interações dos fatores naturais e, conseqüentemente, temos uma mudança no quadro natural, a paisagem.

Nesse enfoque, de alterações do ambiente natural, causadas pelo homem, podemos falar de criação de ecossistemas artificiais ou de paisagens artificiais.

Em 1980, Buchwald classificou essas partes dos ecossistemas naturais alterados em três categorias: espaços com utilização urbano-industrial; espaços com utilização para produção agrícola intensiva; espaços com utilização agrícola e florestal extensiva.

Nesse artigo interessa-nos o primeiro tipo de espaço, ao qual convencionamos denominar ecossistemas ou paisagem urbano-industrial. Utilizaremos os termos ecossistemas e paisagem como sinônimos, apenas para facilidade de abordagem. $\mathrm{Na}$ verdae carecemos, no Brasil, de uma definição precisa do que seja ecossistema. Cremos, porém, que a diferenciação básica dos dois termos devesse embasar-se numa relação de escalas diferenciada.

Os ecossistemas urbano-industriais caracterizam-se por serem aqueles onde a ação antrópica é mais pronunciada e, como já dissemos no início, são os habitados pela maior parte da população brasileira.

Podemos ter uma síntese das alterações, com relação aos ambientes naturais, observando-se 0 quadro a seguir.

A ação do homem afeta principalmente o clima, o solo, o ciclo hídrico, o relevo, a vegetção e a fauna. Ora, havendo alterações nos fatores isolados, é de se esperar uma nova interação e criação de outro tipo de ambiente e por conseguinte nova paisagem.

A alteração do meio natural que melhor se pesquisou até hoje é a climática. A tabela a seguir dá a idéia das alterações observáveis em regiões densamente construídas. 


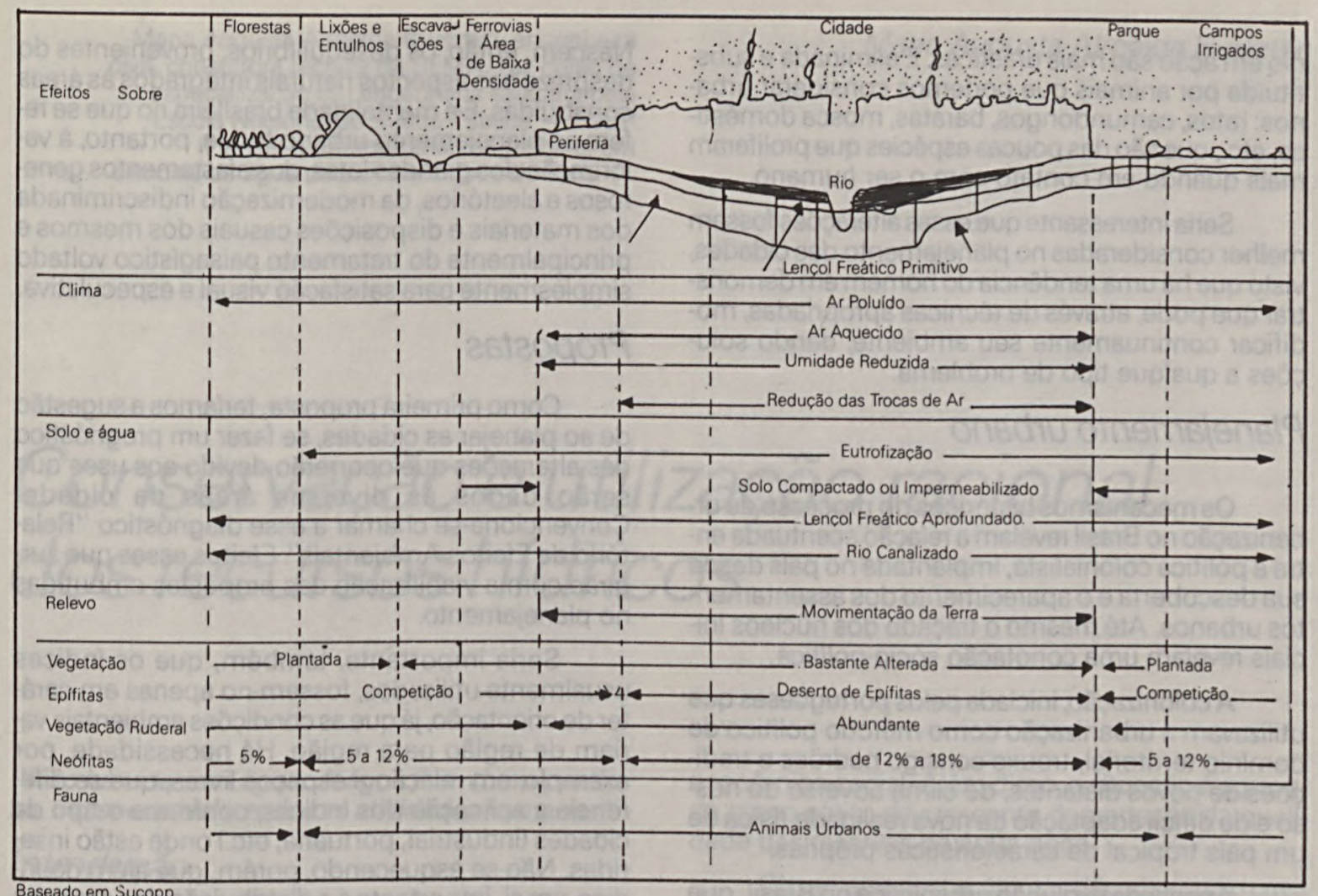

Média da mudança dos componentes meteorológicos devido à urbanização excessiva (segundo Landsberg, 1968)

\begin{tabular}{|c|c|c|}
\hline Componente & Tipo & $\begin{array}{l}\text { Comparação com } \\
\text { áreas não construidas } \\
\end{array}$ \\
\hline Poluiçăo do ar & $\begin{array}{l}\text { Núcleo de condensação } \\
\text { Poluiçăo gasosa }\end{array}$ & $\begin{array}{r}10 \text { vezes mais } \\
5-25 \text { vezes mais }\end{array}$ \\
\hline Nuvens & $\begin{array}{l}\text { Cobertura } \\
\text { Névoa linverno) } \\
\text { Névoa (verão) }\end{array}$ & $\begin{array}{l}5-10 \% \text { mais } \\
100 \% \text { mais } \\
30 \% \text { mais }\end{array}$ \\
\hline Precipitação & $\begin{array}{l}\text { Chuva total } \\
\text { Com mais de } 5 \mathrm{~mm} \text { de } \\
\text { chuva } \\
\text { Neve }\end{array}$ & $\begin{array}{r}5-10 \% \text { mais } \\
10 \% \text { mais } \\
5 \% \text { menos }\end{array}$ \\
\hline Umidade relativa & $\begin{array}{l}\text { Inverno } \\
\text { Verăo }\end{array}$ & $\begin{array}{l}2 \% \text { menos } \\
8 \% \text { menos }\end{array}$ \\
\hline Radiaçåo & $\begin{array}{l}\text { Radiação total } \\
\text { Ultravioleta (inverno) } \\
\text { Ultravioleta (verăo) } \\
\text { Insolaçåo }\end{array}$ & $\begin{array}{r}15.20 \% \text { menos } \\
30 \% \text { menos } \\
5 \% \text { menos } \\
5-10 \% \text { menos }\end{array}$ \\
\hline Temperatura & $\begin{array}{l}\text { Média anual } \\
\text { Minima de inverno } \\
\text { Dias de calefação }\end{array}$ & $\begin{array}{r}0,5-1^{\circ} \mathrm{C} \text { mais alta } \\
1-2^{\circ} \mathrm{C} \text { mais alta } \\
10 \% \text { menos }\end{array}$ \\
\hline Velocidade do vento & $\begin{array}{l}\text { Média anual } \\
\text { Calmaria }\end{array}$ & $\begin{array}{r}10-20 \% \text { menos } \\
5.20 \% \text { mais }\end{array}$ \\
\hline
\end{tabular}

Quanto às alterações relativas aos outros fatores ambientais, apesar de haver mudanças substanciais, são ainda pouquíssimo estudadas e por isso pouco compreendidas.
Sabe-se que as superfícies das cidades, por serem impermeabilizadas, impedem que a água das chuvas chegue ao lençol freático e por isso é necessário toda uma rede de canalização, para conduzir as águas pluviais para fora das cidades. Isso provoca a necessidade de alargar os cursos d'água principais, retificá-los ou mesmo canalizá-los. O que se está fazendo na realidade é apenas transferir o problema de enchentes de uma região a montante, para outra a juzante. As retificações de rios que eram tidas como solução para muitos problemas, estão hoje sendo postas em dúvida pelos danos que causam, entre outros, aprofundamento do leito dos rios devido erosão e rebaixamento de lençol freático (Buchwald, 1977).

A vegetação nas áreas urbanizadas é quase totalmente retirada, agravando os problemas anteriormente mencionados, já que têm um importante papel no armazenamento de água nos ecossistemas. Por outro lado, a flora nativa é quase que praticamente substituída por flora exótica ruderal (observação: a flora ruderal vem a ser a flora que se torna subespontânea nas cidades, tendo a característica de resistir às condições externas de falta d'água, solo eutrofizado, altas temperaturas, podendo, por exemplo, crescer entre pedras do calçamento urbano).

Em relação à fauna, as condições de extermí- 
nio em ação são mais drásticas. É eliminada e substituída por animais que podemos considerar urbanos: ratos, camundongos, baratas, mosca doméstica, etc., que são das poucas espécies que proliferam mais quando em contato com o ser humano.

Seria interessante que essas alterações fossem melhor consideradas no planejamento das cidades, visto que há uma tendência do homem em demonstrar que pode, através de técnicas apropriadas, modificar continuamente seu ambiente, dando soluções a qualque tipo de problema.

\section{Planejamento urbano}

Os mecanismos históricos do processo de urbanização no Brasil revelam a relação acentuada entre a política colonialista, implantada no país desde sua descoberta e o aparecimento dos assentamentos urbanos. Até mesmo o traçado dos núcleos iniciais revelam uma conotação sócio-política.

A colonização, iniciada pelos portugueses que utilizavam a urbanização como método político de domínio territorial, trouxe consigo padrões e tradições de povos distantes, de clima adverso do nosso e de difícil adaptação da nova realidade física de um país tropical de características próprias.

Apesar da evolução urbanística no Brasil, que tomou novos rumos por força das alterações trazidas com a "conscientização" de sua tropicalidade e com o próprio desenvolvimento do país, denotando caráter cultural e inovativo, nota-se que esses fatores foram gradativamente superados pelo capital. O planejamento urbano está, portanto, inserido na estratégia geral de consumo: grande preocupação com o sistema viário eficiente, a setorização das atividades, visando a funcionalidade e proporcionalização dos espaços com o objetivo do "equilíbrio numérico" das diversas áreas urbanas.

Com relação ao "equilíbrio numérico", foram criadas áreas mínimas e índices de ocupação, que em muito facilitam a deturpação e degradação da qualidade dos espaços urbanose, conseqüentemente, da qualidade de vida. No Brasil, para as áreas verdes, por exemplo: sufocam-se as habitações em lotes desnudos, numa união de concreto e asfalto, enquanto que em trechos isolados reserva-se, em parques monumentais, um pouco do ambiente natural.
Nascem, então, os desequilíbrios, provenientes do desprezo aos aspectos naturais integrados às áreas construídas. E a mentalidade brasileira no que se refere ao planejamento urbano tende, portanto, à valorização dos grandes lotes, dos afastamentos generosos e aleatórios, da modernização indiscriminada dos materiais e disposições casuais dos mesmos e principalmente do tratamento paisagístico voltado simplesmente para satisfação visual e especulativa.

\section{Propostas}

Como primeira proposta, teríamos a sugestão de ao planejar as cidades, se fazer um prognóstico das alterações que ocorrerão devido aos usos que serão dados às diversas áreas da cidade. Convenciona-se chamar a esse diagnóstico "Relatório de Efeitos Ambientais". Efeitos esses que surgirão com a viabilização das propostas embutidas no planejamento.

Seria importante, também, que os índices usualmente utilizados, fossem-no apenas em caráter de orientação, já que as condições ambientais variam de região para região. Há necessidade, por exemplo, em relação a espaços livres, que se diferencie a aplicação dos índices, conforme o tipo de cidades (industrial, portuária, etc.) onde estão inseridas. Não se esquecendo, porém, que além do índice, em si, importante é a distribuição dos espaços livres dentro das cidades.

Acreditamos que a contribuição da ecologia ao planejamento das cidades, será justamente o de orientar quanto ao ordenamento desses espaços.

\section{Bibliografia}

1. BUCHWALD \& HARD, Engel. Handunch für planung gestaltung und schutz der umwelt. Munique, 1980.

2. CAIDAS, Linda et alii. Manutenção do ecossistema. Brasília, Ed. Universidade de Brasília, 1976.

3. LANDSBERG. Climates and urban planning. Bruxelas, SYMPOSIUM ON URBAN CLIMATES AND BUILDING CLIMATOLOGY, 1968.

4. RECCINI. Informe sobre crescimento populacional. Buenos Aires, 1969

5. SUKOPP \& KUNICK. Die Gross-Stadt als gegenstand ökologischer forschung -TUB 5. Berlin. Zeitsch. der Tedn. Universität Berlin, 5. jr. 